\title{
Bilateral Cochlear Implantation in Facioscapulohumeral Muscular Dystrophy Presenting Sensorineural Hearing Loss
}

\author{
Jin Youp Kim ${ }^{1}$, Mun Young Chang ${ }^{1}$, Chong Sun Kim ${ }^{2}$, and Young Ho Kim ${ }^{1}$ \\ ${ }^{I}$ Department of Otorhinolaryngology-Head and Neck Surgery, Boramae Medical Center, \\ Seoul Metropolitan Government-Seoul National University, Seoul; and ${ }^{2}$ Soree Ear Clinic, Seoul, Korea
}

\author{
감각신경성 난청을 동반한 안면견갑상완근이영양증 환자에서 양측 인공와우이식술 시행한 1 예 \\ 김진엽 ${ }^{1} \cdot$ 장문영 ${ }^{1} \cdot$ 김종선 $^{2} \cdot$ 김영호 $^{1}$ \\ 서울대학교 의과대학 보라매병원 이비인후과학교실, ${ }^{1}$ 소리 귀 클리닉 ${ }^{2}$
}

\author{
Received June 13, 2016 \\ Revised August 11, 2016 \\ Accepted August 16, 2016 \\ Address for correspondence \\ Young Ho Kim, MD, PhD \\ Department of Otorhinolaryngology- \\ Head and Neck Surgery, \\ Boramae Medical Center, \\ Seoul Metropolitan Government- \\ Seoul National University, \\ 20 Boramae-ro 5-gil, Dongjak-gu, \\ Seoul 07061, Korea \\ Tel $+82-2-870-2442$ \\ Fax +82-2-870-3863 \\ E-mail yhkiment@gmail.com
}

Facioscapulohumeral muscular dystrophy (FSHD) presents a muscular weakness in the face, shoulder girdle, and legs. In addition, bilateral, progressive, high-frequency sensorineural hearing loss (SNHL) can be expressed. A 3-year-old boy visited with bilateral facial paralysis and bilateral hearing loss. Audiological evaluations revealed bilateral, progressive, sloping SNHL and bilateral hearing aids was used for more than 3 years. Cochlear implantation was carried out on left side when he was 6 years old and on right side when he was 7 years old. Seven months after cochlear implantation on left side, his shoulder muscle weakness was found and the genetic analysis showed decreased D4Z4 repeat size in 4qA allele confirming a diagnosis of FSHD. After auditory rehabilitation using electroacoustic stimulation, his hearing and speech perception were much improved. This case suggests that cochlear implantation can be beneficial in patients with SNHL associated with FSHD.

Korean J Otorhinolaryngol-Head Neck Surg 2017;60(4):187-90

Key Words Cochlear implantation · Electroacoustic stimulation ·

Facioscapulohumeral muscular dystrophy $\cdot$ Hearing loss.

\section{Introduction}

Facioscapulohumeral dystrophy (FSHD) is often cited as the third most common form of muscular dystrophy. ${ }^{1)}$ It is an autosomal dominant muscular dystrophy caused by contraction of a region of DNA on chromosome 4 containing repeated DNA sequences called D4Z4 repeats. ${ }^{2)}$ Patients with FSHD represent muscular weakness in the face, shoulder girdle, and legs. The most severe form has onset in childhood and is associated with fewer D4Z4 repeats. High-frequency senso-

This is an Open Access article distributed under the terms of the Creative Commons Attribution Non-Commercial License (http://creativecommons.org/licenses/by-nc/4.0) which permits unrestricted non-commercial use, distribution, and reproduction in any medium, provided the original work is properly cited. rineural hearing loss (SNHL) and retinal vasculopathy can be a part of this severe phenotype. ${ }^{2)}$ In the point of rarity of reports on CI in FSHD, we report here a clinical case of a patient with FSHD that has underwent bilateral CI as a treatment for severe SNHL.

\section{Case}

A 3-year-old boy with bilateral hearing loss and bilateral facial paralysis visited at otolaryngology clinic. Bilateral hearing loss was identified in newborn screening test and auditory brainstem response test (right side: $45 \mathrm{~dB}$, left side: $55 \mathrm{~dB}$ ) when he was 4 months old. He has used bilateral hearing 
aids from 16 months after birth. Bilateral facial paralysis was incidentally noticed at our clinic when he was 3 years old. The progress of facial paralysis was insidious and continuous, not recurrent nor episodic. We investigated his previous photos to speculate onset time of his facial paralysis, and it was ob- vious when he was 23 months old. In cranial nerve (CN) examinations, other CNs were intact except for CN VII and VIII. High-resolution computerized tomography of the temporal bone and internal auditory canal magnetic resonance imaging showed no anomaly of inner ear. The initial pure

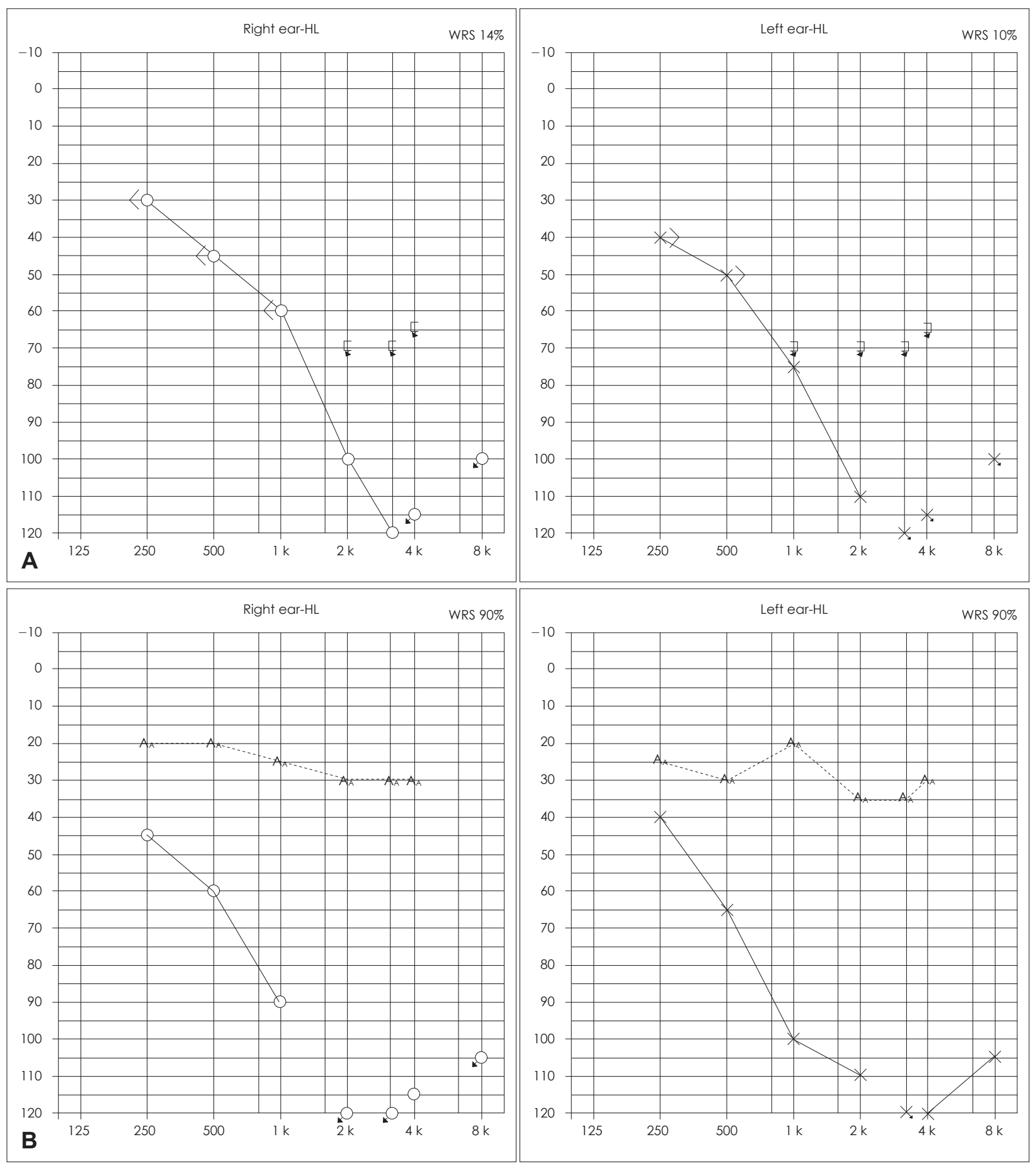

Fig. 1. The initial audiogram before cochlear implantation $(\mathrm{Cl})$ shows bilateral ski-slope shaped high tone sensorineural hearing loss and poor word recognition scores (WRS) (unaided) (A). The audiogram results after bilateral Cl (left ear: postoperative 18 months, right ear: postoperative 8 months). The preservation of low tone hearing and improved $\mathrm{Cl}$-aided pure tone threshold/WRS are observed on both sides (B). 


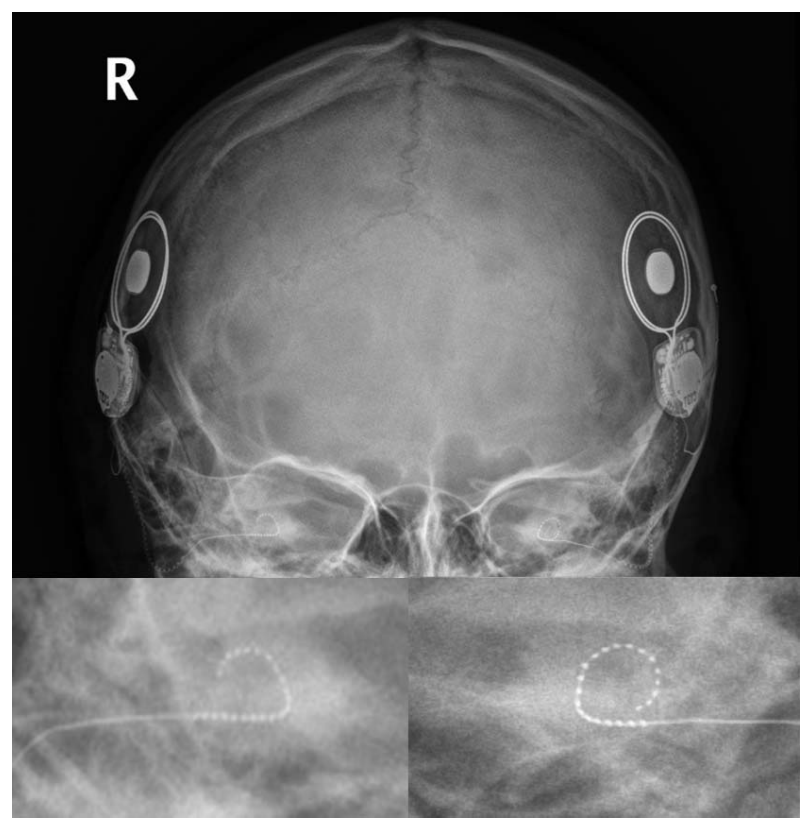

Fig. 2. Radiographic findings after cochlear implantation. Bilateral full-length electrode array insertion into cochlea is seen.

tone audiogram showed bilateral ski-slope shaped high tone SNHL (Fig. 1A). The initial speech audiometry was right $14 \%$ and left $0 \%$. Three years after use of bilateral hearing aids, hearing gain and speech perception were not high. Because the benefit of conventional hearing aids was only minimal, CI was planned. CI (nucleus 422, standard electrode arrays with full-length insertions, round window approach) was carried out on left side when he was 6 years old and on right side when he was 7 years old (Fig. 2). The device and technique were identical on both sides. In addition, a standardized "soft surgery" technique suggested by Lehnhardt" and intraoperative administration of intravenous dexamethasone $(0.25 \mathrm{mg} / \mathrm{kg})$ were used on both sides. After CI, intraoperative Neural Response Telemetry, a noninvasive direct physiologic measurement of evoked compound action potentials of the auditory nerve via the implant, showed all positive in 22 channels on both sides. The low tone hearing preservation was confirmed in postoperative audiometry and improved CI-aided pure tone threshold/word recognition scores were observed on both sides (Fig. 1B). Six months after surgery on left side, categories of auditory performance (CAP) score was improved from 4 to 6 and speech perception (open-set, audio only) was improved from $40 \%$ to $100 \%$. On the other hand, CAP score was 6 and speech perception (open-set, audio only) was $96 \%$, when he wore the device on right side only at 5 months after $\mathrm{CI}$ on right side. He is taking postoperative auditory rehabilitation using electroacoustic stimulation (EAS). Seven months after CI on left side, his shoulder muscle weakness was found and the genetic analysis showed decreased D4Z4 repeat size in 4qA allele [D4Z4 repeat size $(\mathrm{kb})$ and haplotype analysis: $90 \mathrm{~kb}(4 \mathrm{qA}) / 21 \mathrm{~kb}$ $(4 q A)]$ confirming a diagnosis of FSHD.

\section{Discussion}

FSHD is an autosomal dominant muscular dystrophy caused by contraction of a region of DNA on chromosome 4 containing repeated DNA sequences called D4Z4 repeats. People without the disease have $>10$ D4Z4 repeats, while people with the disease have 1-10 D4Z4 repeats (EcoRI fragment, $38 \mathrm{~kb}$, EcoRI/BlnI fragments, $35 \mathrm{~kb}$ ). ${ }^{2)}$ High-frequency SNHL and retinal vasculopathy can be presented in a severe phenotype of FSHD expressed in childhood and associated with fewer D4Z4 repeats. ${ }^{2)}$ In most cases, facial muscle paralysis develops initially, followed by muscular weakness of shoulders and arms. Extramuscular manifestations have often been reported in patients with FSHD and auditory impairment is the most frequently detected manifestation. ${ }^{4}$ Approximately $60 \%$ of individuals with FSHD have an abnormal audiogram with high-tone SNHL. ${ }^{4}$ SNHL in patients with FSHD initially involves the higher frequency range and tends to involve the lower frequencies as one grows older, and a primary involvement of the outer hair cells has been speculated. ${ }^{5)}$ Auditory brainstem response studies in patients with FSHD revealed normal results, suggesting the integrity of auditory neural pathways. ${ }^{6,7)}$ However, transiently evoked otoacoustic emissions proved to be absent in FSHD patient, even in patients with clinically normal or near-normal hearing, which supports association with cochlear damage. ${ }^{8)}$

Although the reason for the hearing loss is not yet understood, high-tone SNHL in childhood-onset FSHD can be more profound than that in adults. Therefore if failed to detect their hearing losses, they may have delayed language development and even the false perception of cognitive impairment. ${ }^{9)}$ Consequently, hearing should be tested routinely in infants and preschool children diagnosed with FSHD. ${ }^{10)}$ In our case, bilateral SNHL was initially identified in the newborn hearing screening test, followed by progressive bilateral facial paralysis. Muscular weakness of his upper extremities was detected since his age of 6 years, which enabled the diagnosis of FSHD finally. Late or progressive development of the muscular weakness findings including shoulders and arms may make the early diagnosis of FSHD difficult. If FSHD patients have 
hearing loss more severe than mild degree, conventional hearing aids can be considered first. However, in cases of little benefit, other hearing rehabilitations need to be decided. Especially, in pediatric FSHD cases, more effective one including CI should be selected as soon as possible.

We need to pay attention to residual hearing shown in FSHD cases with severe hearing loss for better auditory rehabilitation. Residual hearing preserved after CI has been reported to increase hearing performance-especially noisy environments, improve music perception, enable to listen sound of a more natural quality. ${ }^{11-13)}$ The type of insertion of CI electrode arrays can be partial or full-length. Skarzynski, et al. ${ }^{12)}$ reported $100 \%$ of preservation of some residual hearing with partial insertion (Med-El devices, $20 \mathrm{~mm}$, Innsbruck, Austria) in 9 children. Partial insertion technique would possibly avoid damage to the lower frequency area of the cochlea. On the contrary, full-length insertion technique may have a potential of damage to the lower frequency region. Because residual hearing may be lost after CI, the insertion type of CI electrode arrays needs to be considered carefully. However, we have to consider that children with hearing impairment tend to have a greater risk of progressive hearing loss than adults. ${ }^{14)}$ Recent study evaluated postoperative residual hearing after pediatric CI. ${ }^{14)}$ They found that approximately $45 \%$ had complete hearing preservation and $90 \%$ had partial hearing preservation. ${ }^{14)}$ For the residual hearing preservation with fulllength electrode array insertions, meticulous surgical technique and safe electrode array design are essential. If the preservation of residual hearing is achieved, the application of EAS can be considered. With a successful full-length insertion of standard-length electrode arrays and preservation of residual hearing, EAS mode need to deactivate low-frequency electrodes for the acoustic rehabilitation. And, with loss of lowfrequency residual hearing by progressive hearing loss, the electrical stimulation on the low-frequency region can be activated.

Although CI in FSHD patients was not reported to date, his postoperative hearing and speech perception in this case were good. Therefore we think CI in FSHD cases with severe hearing loss can be one of good rehabilitation candidates. Because FSHD cases with hearing impairment usually present high-tone SNHL, post-CI auditory rehabilitation using
EAS need to be considered actively.

In conclusion, to the best of our knowledge, this is the first case that FSHD patient with bilateral severe SNHL underwent CI. Our surgical results suggest that CI in FSHD patients with severe hearing loss may be helpful for their auditory rehabilitation. Because high-frequency SNHL is typical feature of FSHD with hearing impairment, post-CI auditory rehabilitation using EAS should be considered.

\section{Acknowledgments}

This study was supported by a clinical research grant provided by Seoul National University Boramae Medical Center.

\section{REFERENCES}

1) Castellano V, Feinberg J, Michaels J. Facioscapulohumeral dystrophy: case report and discussion. HSS J 2008;4(2):175-9.

2) Lutz KL, Holte L, Kliethermes SA, Stephan C, Mathews KD. Clinical and genetic features of hearing loss in facioscapulohumeral muscular dystrophy. Neurology 2013;81(16):1374-7.

3) Lehnhardt E. [Intracochlear placement of cochlear implant electrodes in soft surgery technique]. HNO 1993;41(7):356-9.

4) Lemmers RJ, Miller DG, van der Maarel SM. Facioscapulohumeral muscular dystrophy. Seattle, WA: Gene reviews;2014.

5) Voit T, Lamprecht A, Lenard HG, Goebel HH. Hearing loss in facioscapulohumeral dystrophy. Eur J Pediatr 1986;145(4):280-5.

6) Taylor DA, Carroll JE, Smith ME, Johnson MO, Johnston GP, Brooke MH. Facioscapulohumeral dystrophy associated with hearing loss and Coats syndrome. Ann Neurol 1982;12(4):395-8.

7) Gieron MA, Korthals JK, Kousseff BG. Facioscapulohumeral dystrophy with cochlear hearing loss and tortuosity of retinal vessels. Am J Med Genet 1985;22(1):143-7.

8) Balatsouras DG, Korres S, Manta P, Panousopoulou A, Vassilopoulos D. Cochlear function in facioscapulohumeral muscular dystrophy. Otol Neurotol 2007;28(1):7-10.

9) Darras BT, Tawil R. Predicting hearing loss in facioscapulohumeral muscular dystrophy. Neurology 2013;81(16):1370-1.

10) Tawil R, van der Maarel S, Padberg GW, van Engelen BG. 171st ENMC international workshop: standards of care and management of facioscapulohumeral muscular dystrophy. Neuromuscul Disord 2010;20(7):471-5.

11) Büchner A, Schüssler M, Battmer RD, Stöver T, Lesinski-Schiedat A, Lenarz T. Impact of low-frequency hearing. Audiol Neurootol 2009;14 Suppl 1:8-13.

12) Skarzynski H, Lorens A, Piotrowska A, Anderson I. Partial deafness cochlear implantation in children. Int J Pediatr Otorhinolaryngol 2007;71(9):1407-13.

13) Soda-Merhy A, Gonzalez-Valenzuela L, Tirado-Gutierrez C. Residual hearing preservation after cochlear implantation: comparison between straight and perimodiolar implants. Otolaryngol Head Neck Surg 2008;139(3):399-404.

14) Brown RF, Hullar TE, Cadieux JH, Chole RA. Residual hearing preservation after pediatric cochlear implantation. Otol Neurotol 2010;31(8):1221-6. 